\title{
Acknowledgments and Remarks from the Editor-in-Chief
}

The second volume of Contemporary Challenges: The Global Crime, Justice and Security Journal marks our expansion and development. To truly reflect the global reach of our thematic focus, we decided to open submissions for authors outside of the University of Edinburgh and we are excited to have their contributions featured in the present volume. The articles and commentaries in this edition connect a variety of disciplines, including law, criminology, international relations, and political science; cover multiple regions of the world, addressing transnational and international issues; and draw on a wealth of approaches from feminist critiques and transitional justice concepts to zemiology and green criminology.

In her contribution, Woodward analyses the Deepwater Horizon explosion, applying a zemiological and green criminological lens to the causes of the catastrophe. Woodward finds that even though green criminology is increasingly cognisant of social harms, zemiological perspectives are, because of their independence from legal frameworks, ultimately still valuable for comprehensively understanding transnational environmental harms.

Florenz and Hawke propose an unusual case study for scholars interested in transitional justice: the US. They argue that recent US history, culminating in the Capitol Riots in early 2021, exposed a divided society in need of healing. The authors theorise that transitional justice scholars should scrutinise current US attempts at restoring unity as this may allow for the discovery of new, and the reassessment of old, transitional justice and democratic reform instruments. 
In her article, Kulić scrutinises the use of citizenship deprivation as a counterterrorism measure. Investigating what causes the spread and rising popularity of citizenship deprivation, Kulić critically assesses its effectiveness, arguing that rather than addressing the problem of terrorism, citizenship deprivation shifts it, thereby potentially undermining counterterrorism efforts.

Zimmermann de Meireles Philippi takes stock of Southern criminology's contributions, exploring future avenues for the development of criminological knowledge. Instead of exclusively or predominantly hailing Southern criminology's challenge to the hegemony of criminological theory and knowledge emerging from the Global North, Zimmermann de Meireles Philippi argues that Southern criminology's greatest contribution to the academic discourse is its foregrounding of the continuing criminogenic effects of colonialism.

Kaptan sets out to find an answer to the question, why, given the clear military supremacy of one side to the conflict, the war in Yemen is still ongoing without an end in sight. Employing state-level analysis, she discusses three possible explanations and finds that conventional approaches relying on "winning hearts and minds" and military inadequacy arguments fail to satisfactorily account for the continuation of the conflict.

Applying Agnew's general strain theory, Niggeler investigates conflict-related sexual violence in the Democratic Republic of the Congo. She focuses on perpetrators in an attempt to understand what drives the violence, generating important insights for the design of prevention measures. Niggeler finds that conventional explanations focusing on the satisfaction of sexual desires or superior orders to use rape as a weapon of war paint an incomplete picture.

Whitchurch investigates the zeal with which war crime prosecutions are pursued in Serbia versus Bosnia and Herzegovina, scrutinising the impact of international incentives, judicial challenges, and ethnic composition. Her finding that ethnic composition is the most pivotal impacting factor can be used to shape measures surrounding war crimes prosecutions in future contexts. 
Kovar exposes the continuing relevance of Durkheimian ideas for contemporary crime and punishment theory, focusing on inequalities in society. Drawing on the 2011 riots in London and the Black Lives Matter movement as case studies, Kovar argues that Durkheimian concepts are valuable tools for the recognition of inequalities, but that, ultimately, a shift in morality is required for this recognition to translate into practical changes.

Hale scrutinises the legal difficulties connected to preventing genocide. Shedding light on Article 3 of the Genocide Convention, Hale argues that the inchoate acts listed in the article generate a preventative framework, which, however, is difficult to operationalise since proving special intent to commit genocide is particularly complicated with regards to inchoate crimes.

Robertson analyses the impact conventions have on eliciting cooperation between law enforcement agencies across states. Focusing on transnational drug trafficking, Robertson argues that even though cooperation between police forces existed prior to the relevant UN conventions, legal codification of existing practices facilitates police cooperation and helps develop jurisprudence in the field.

Knap investigates femicide, arguing that this global and complex phenomenon cannot truly be grasped without the consideration of intersectional and multilateral approaches. She focuses specifically on the institutional and social structures of culture and class, shedding light on the ways in which these two factors impact femicide on the micro, meso, and macro levels and paving the way for improved legislation.

Drawing on coltan mining in the Democratic Republic of the Congo and lithium extraction in Argentina, Bolivia, and Chile, Lawrence argues that renewable resources and their markets are in need of closer scrutiny by criminologists. Lawrence demonstrates the superiority of green criminological approaches in relation to the case studies and focuses specifically on the emergent concept of "ecocide."

Provan analyses the relationship between crime and conflict, arguing that conventional approaches suggesting that one breeds the other and vice versa are overly simplistic. Instead, Provan proposes that it is the interrelationship between crime and security, development, and 
governance, on the one hand, and conflict and security, development, and governance, on the other, that explains the seeming entanglement of crime and conflict.

Contemporary Challenges would not be possible without the generous support our team receives from multiple sides. We would like to thank: Dr Andy Aydın-Aitchison for his words of advice and encouragement as our academic patron; Rebecca Wojturska for her incessant efforts to increase the journal's reach and her work in the background; the former editorial board and specifically, former Editor-in-Chief Frederik Florenz and former Deputy Editor-inChief June Shuler for their continued - and infectious - enthusiasm and support; our authors for their drive, patience, and engagement. Lastly, as Editor-in-Chief, I would like to express my deep appreciation of the current editorial board and specifically, Kağan Sürücü, Deputy Editor-in-Chief. Without the benefit of having met face-to-face once, you have proven to be an incredible team, working hard to produce and develop the journal. Thank you.

Alicja Polakiewicz

Editor-in-Chief 